\title{
Mid-Term Review of ADEPT Metal-On-Metal Hip Prosthesis. Functional, Radiological and Metal Ion Analysis
}

\author{
James G. A. Plant, Gareth H. Prosser, Ben J. Burston, Stephen J. Edmondston, Piers J. Yates
}

Department of Orthopaedics, Fremantle Hospital, Fremantle, Australia.

Email: jgap@hotmail.com

Received January $9^{\text {th }}, 2014$; revised February $11^{\text {th }}, 2014$; accepted February $20^{\text {th }}, 2014$

Copyright ( 2014 James G. A. Plant et al. This is an open access article distributed under the Creative Commons Attribution License, which permits unrestricted use, distribution, and reproduction in any medium, provided the original work is properly cited. In accordance of the Creative Commons Attribution License all Copyrights (C) 2014 are reserved for SCIRP and the owner of the intellectual property James G. A. Plant et al. All Copyright (C) 2014 are guarded by law and by SCIRP as a guardian.

\section{ABSTRACT}

Background: There is much interest regarding metal-on-metal implants in medical and general media. Much of this has been regarding failure of specific implant systems and metal ion toxicity. We present our early mid-term experience of the ADEPT metal-on-metal system which has both modular and non-modular hip options. Methods: Functional assessment, blood metal ion quantification, and radiographic analysis were performed for the modular and non-modular ADEPT variants. Fifty implants were implanted with a mean follow up time of 28 months. Unpaired t-tests were used to compare modular and resurfacing groups, standardised hip scores were used to compare function to conventional total hip arthroplasty. Results: Metal ion levels were significantly higher in modular prostheses compared to resurfacing implants, but not at "harmful" levels (as determined by a previous metal-on-metal implant recall). Functional outcomes were excellent and revision rates were lower than expected. Conclusions: At our institution we have good outcomes with the ADEPT hip prosthesis. Though patient selection and implant position are crucial, poor performance of metal-on-metal hip replacements is implant specific.

\section{KEYWORDS}

Metal-On-Metal; Arthroplasty; Modular; Resurfacing; ADEPT; Chromium Ions; Cobalt Ions; Functional Review

\section{Background}

Metal-on-metal hip arthroplasty has been in use since Dr Wile's publication in 1938 [1]. The prevalence of modern designs utilising this particular hard-on-hard bearing surface is testament to its many desirable features when compared to conventional metal-on-polyethylene systems. Metal-on-metal systems have been shown to have a wear profile nearly two orders of magnitude less than their metal-on-poly counterparts [2]. The rate of wear decreases with increasing head size thanks to in vivo phenomenon of a fluid-film layer linking the highly congruent couples (after initial bedding-in). Reduced wear therefore reduces particle osteolysis and improves implant longevity. Other advantageous features of the large head size include increased stability and range of motion.

Dislocation is rare in modern larger head metal-onmetal arthroplasty not only because of the increased "jump distance" of the head, but as a result of a suctionfit effect from the fluid-film layer [3]. The lower wear rates of metal-on-metal surfaces were hoped to alleviate torque concerns regarding larger head sizes [4]. There has recently been widespread concern regarding metal-on-metal bearing surfaces, both in the medical literature and in the general media. The most pronounced of the failures was the Articular Surface Replacement (ASR), globally recalled by DePuy (Warsaw, USA) in August 2010. Other metal-on-metal systems have been shown to have a higher than expected revision rate $[5,6]$ whilst others have been shown to have excellent mid- 
term results [7]. A recent review [8] of the National Joint Registry of England and Wales of over 30,000 metal-on-metal implants (of over 400,000 stemmed total hip replacements) concludes that metal-on-metal stemmed implants should not be implanted due to their high comparative failure rate. The authors also report an earlier failure rate with larger diameter head sizes and suggest a failure of fluid-film lubrication and trunnion wear from the increased torque as possible explanations. The Joint Registries however do not give functional assessment and patient satisfaction scores, which is a limitation noted in that particular review.

As there are significant differences between metal-onmetal prostheses, each design should be individually evaluated. The ADEPT system consists of a solid cobalt-chrome (CoCr) acetabular component with either a $\mathrm{CoCr}$ resurfacing head or a $\mathrm{CoCr}$ modular head with a 12/14 taper. The implant is made by Finsbury Orthopaedics (Leatherhead England) and was bought by DePuy (Warsaw, USA) in 2009. The ADEPT has evolved from the (Finsbury) McMinn and Birmingham metal-on-metal designs and is manufactured from cast, high carbon cobalt chrome featuring a high surface fraction of carbides. The carbides prevent cobalt chrome matrix abrasion and thereby reduce wear. The modular system head is supplied in a range with differing offset for each size; there is no additional sleeve component.

The full $180^{\circ}$ hemispherical, press-fit acetabular component is backed by a cast-in cobalt chrome, hydroxyapatite coated surface and is ideally positioned at $30^{\circ}$ to $35^{\circ}$ from vertical in the AP plane and $20^{\circ}$ to $25^{\circ}$ anteversion. It is crucial to cover the load axis to prevent rim loading and subsequent increased wear.

Clearance (head-to-cup diameter difference) is critical to achieve dynamic fluid film lubrication, the replenishing of which occurs on unloading the articulating surfacees during swing phase. The ADEPT features a clearance around $200 \mu \mathrm{m}$, modeled to minimise torque and maximise lubrication with synovial fluid of the viscosity expected in a replaced joint [9].

We performed a retrospective review of our Adept metal-on-metal arthroplasty patients with multifactorial analysis of patient satisfaction, radiographic appearance, and serum metal ion concentrations.

\section{Methods}

Fifty consecutive Adept implants were identified using hospital operating theatre information, clinic records, surgeon logbooks, and cross referencing device company records. Suitable patients for an ADEPT prosthesis had been identified by the lead consultants (GH, PY) and consented for surgery. The specifics of each implant were recorded; as was patient data including BMI, age, gender and reason for surgery. Five patients (six implants) either could not be contacted or refused to attend follow up. Ethical approval for the retrospective review was obtained from the Institutional Human Research Ethics Committee.

Forty-four hips in 37 patients implanted with the Adept hip system by either of two consultant surgeons were reviewed at early to midterm follow up. Thirty-five (95\%) of the patients were male. A Corail (DePuy, Warsaw USA) stem was used for the modular systems. The Corail tapered stem is made of forged titanium alloy (TiAl6V4); extensively coated with hydroxyapatite and has excellent long term results [10]. The posterior approach to the hip was used in all cases. All resurfacing femoral heads were cemented. Postoperative management was according to standard departmental guidelines.

Over a five-month period the identified patients were recalled to clinic for assessment by the consultant or the consultants Fellow, for clinical assessment of hip function. At this time radiographs were taken and blood cobalt \& chromium metal ion concentrations were measured using ICP-MS tecnique. The patients were asked to complete an Oxford Hip Score assessment [11], Western Ontario MacMaster (WOMAC) Osteoarthritis Index questionnaire [12] and a University of California and Los Angeles (UCLA) Activity questionnaire [13]. These scoring systems are validated and widely used [14].

Preoperative, postoperative and review radiographs were analysed. Cup angle, offset, lysis, stem position change, neck thinning, cortical hypertrophy, stress shielding and subsidence were assessed. Dislocations and fractures were individually reviewed. The zones described by Gruen [15] and modified by Johnston [16] were used to assess the stemmed (Corail) replacements. Zones around the femoral resurfacing component were those as described by Steffan at al. [17] in their review of the Birmingham resurfacing system (Figure 1). Charnley

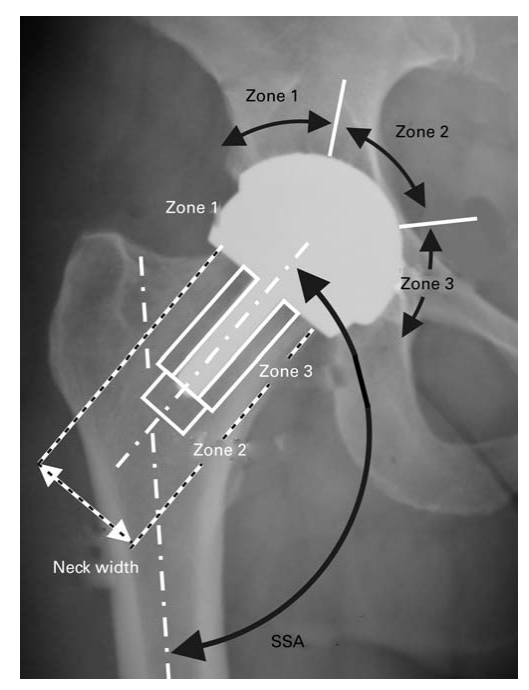

Figure 1. Roentgenogram demonstrating areas and angles used for radiological assessment of resurfacing implant [17]. SSA—stem/shaft angle. 
and DeLee's description of acetabular lysis [18], Engh's classification of stress shielding [19] and Brooker's quantification of heterotopic bone formation [20] were employed.

\section{Statistical Analysis}

For all patient characteristics and dependent variables, descriptive statistics were calculated. Differences between the modular and resurfacing groups were examined using unpaired t-tests. Unpaired t-tests were also used to test for between group differences in patient function outcome measures (Oxford score, WOMAC and UCLA score). The criterion for statistical significance was set at $\mathrm{p}<0.05$.

\section{Results}

There was no statistical difference between the modular and resurfacing populations regarding height or time to review since surgery. The patients with a modular prosthesis were overall slightly older $(\mathrm{p}=0.025)$ and heavier $(p=0.049)$, with a greater BMI $(p=0.019)$ than the resurfacing group (Table 1). Follow-up ranged from two to 60 months post surgery, with a mean time to review of 28 months.

In the resurfacing group, implant head size ranged from $42 \mathrm{~mm}$ (in a female patient) to $58 \mathrm{~mm}$. Mode average was $52 \mathrm{~mm}$ (8 implants). The modular head size ranged from $46 \mathrm{~mm}$ to $56 \mathrm{~mm}$ with a mode average of 48 (9 implants).

\subsection{Radiological Assessment}

Of the 23 resurfacing implants 14 (61\%) were noted to have neck thinning of $2 \mathrm{~mm}$ or more at follow up. There were three neck fractures of resurfacing patients within 6 months of surgery. These were all converted to stemmed implants and followed up as such in the study cohort.

Cup inclination angle measured on an anterior-posterior X-ray ranged between 23 and 53 degrees with a mean of $37^{\circ}$. One resurfacing implant $\mathrm{X}$-ray demonstrated stem lucency, in zone 1. Four stemmed implants had lucent zones. The stem with most lucent areas (zones 1, 7, 8 \& 14) was later revised. A stem with three lucent zones $(1,7,8)$ was the only stem noted to have subsided. The cobalt ion levels in this patient were the second highest at $91 \mathrm{nmol} / \mathrm{L}$. Five patients had heterotopic ossification at follow-up, Brooker grade 2 at worst. One of the 5, with post-traumatic osteoarthritis, had grade 4 heterotopic ossification pre operatively. Neither stress shielding nor cortical hypertrophy were observed in any patient.

\subsection{Function}

Oxford Hip scores were generally very high compared to
THA. Resurfacing scores were on average better than for modular prostheses, but this difference was not signifycant $(p=0.47)$. Mean Oxford hip scores for modular and resurfacing systems were 41.8 and 43.0 respectively (Figure 2). Similarly WOMAC scores were generally very low, indicating excellent function. Resurfacing had a lower mean score (8.7) than modular implants (10.9) but this again was not statistically significant $(\mathrm{p}=0.57$ ) (Figure 3). The mean UCLA scores were 6.0 and 6.3 in the modular and resurfacing groups respectively. There was no significant difference between groups $(\mathrm{p}=0.67)$ (Figure 4).

\subsection{Metal Ion Levels}

Cobalt ion levels were significantly higher $(\mathrm{p}<0.0026)$ in the modular group compared to the resurfacing patients, with tenfold greater variance (Figure 5). All but one of the patients had serum metal ion levels below the threshold used during the ASR recall (cobalt $119 \mathrm{nmol} / \mathrm{L}$, chromium $135 \mathrm{nmol} / \mathrm{L}$ ). The outlier, with a cobalt level of $178 \mathrm{nmol} / \mathrm{L}$, was a patient with a modular implant and lucent lines in 4 zones.

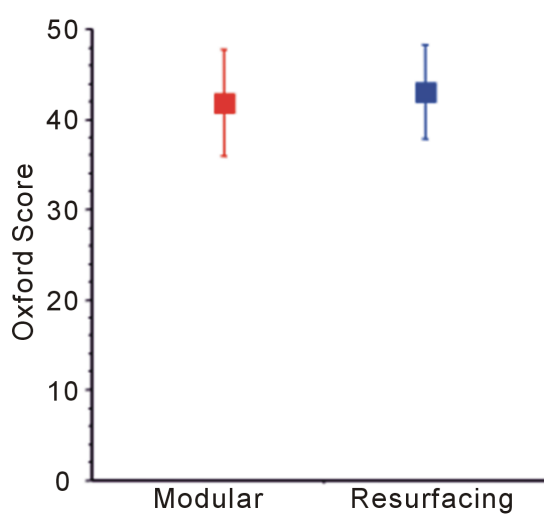

Figure 2. Oxford hip scores-12 questions graded 0 - 4 with a maximum score of 48 (better function = higher score).

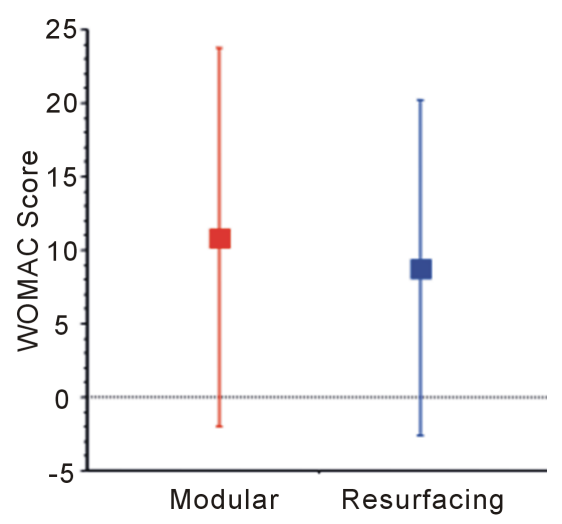

Figure 3. WOMAC scores-cumulative score assessing pain, stiffness and physical function. Maximum score (indicating very poor result) is 100 . 
Table 1. Descriptive statistics, split by category.

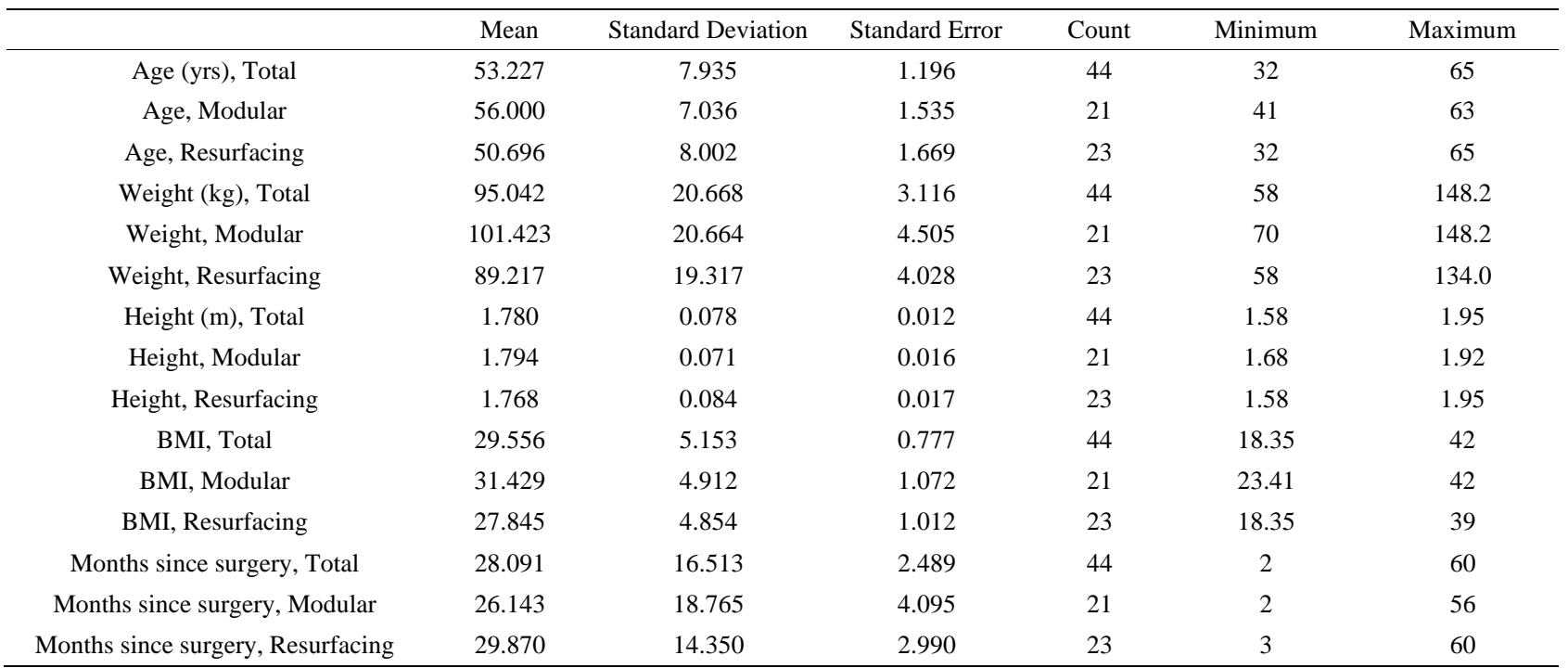

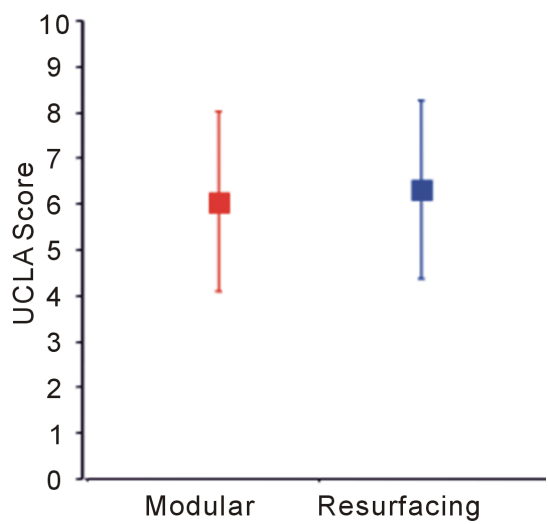

Figure 4. UCLA Activity scores. 1-wholly inactive/dependant, 10 -regularly participates in impact sports.

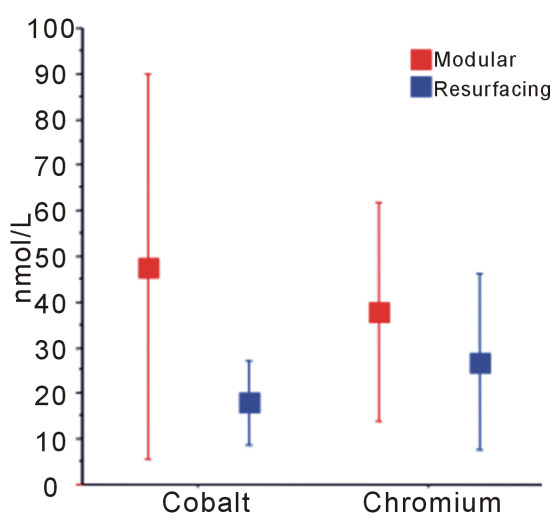

Figure 5. Comparative analysis of metal ion levels.

\section{Discussion}

Revision rate of most resurfacing prostheses is generally higher than for conventional total hip arthroplasty, though the ADEPT prosthesis has the lowest resurfacing revision rate in Australia [21]. In large head (>50 mm) resurfacing (all manufacturers), revision is most commonly for loosening, then neck fracture.

Three of the modular implants in this study were revised Adept resurfacings following neck fracture. Two of these were $52 \mathrm{~mm}$ and $54 \mathrm{~mm}$ heads and were due to direct trauma. The third, with a $48 \mathrm{~mm}$ resurfacing head was spontaneous at 3 months following surgery. Groin pain for two weeks preceded the fracture. All these patients were male.

Suboptimal placement of metal-on-metal acetabular components has been linked to high ion concentrations and failure [22]. Our patients with higher cup inclination angles did not have correspondingly higher metal ion levels though no angle exceeded the $55^{\circ}$ reported by Desy et al. to lead to edge loading and elevated ion levels. In this study, the greatest cup inclination angle was $53^{\circ}$.

Patient reported functional outcome in both groups was extremely good, using validated questionnaires. The Oxford Hip Score can be interpreted thus, $>41$ as excellent, 34 - 41 as good, 27 - 33 as fair, and $<27$ as poor [14]. At mean values of 43 and 41.8 in the resurfacing and modular implants respectively, the functional results of both our patient groups are considered excellent. The UCLA Activity scores had greater variability and averaged around 6 in both groups. This corresponds to "Regularly participates in moderate activities”. Two resurfacing patients scored 10 "Regularly participates in impact sports”.

The stemmed implant with radiological signs of significant loosening went on to be revised. The resurfacing prostheses with a zone one radiolucent line had excellent function, average cobalt ion levels for the resurfacing group $(17 \mathrm{nmol} / \mathrm{L})$, but elevated chromium ion levels at $40 \mathrm{nmol} / \mathrm{L}$ (group mean $26.8 \mathrm{nmol} / \mathrm{L}$ ). 
The resurfacing prosthesis with a pedestal sign had good function but metal ion levels above the mean for resurfacing ADEPTs (Co $28 \mathrm{nmol} / \mathrm{L}, \mathrm{Cr} 67 \mathrm{nmol} / \mathrm{L}$ ).

These findings indicate that plain radiographs are useful screening tools and that metal ion levels can be expected to be elevated in patients with radiolucent lines around their implant on X-ray.

Large head metal-on-metal implants on a trunnion have a high fate of failure in the joint registries, and their use has been cautioned against [8].

In February 2013, the ADEPT 12/14 modular head was withdrawn by DePuy as a result of higher than anticipated revision rates in the 2012 British and Australian registries. The revision rates were $12.1 \%$ at 7 years, and $7.1 \%$ at 3 years respectively. The acetabular component and resurfacing system were not affected.

After this data was gathered, but prior to publication, one modular Adept implant was revised for aseptic loosening. This patient had already been noted to have a Cobalt ion level far in excess of all others in the cohort and above the level deemed "safe" by DePuy during the ASR recall $(119 \mathrm{nmol} / \mathrm{L})$. The same patent had lucent lines in four zones on X-ray at 52 months follow up. The functional scores for this patient were below the mean value for the group (patient scores OHS 37, WOMAC 21, UCLA 6).

Biomechanical analysis of the retrieved implant revealed dendritic synovitis caused by a combination of "normal" metal on metal wear and gross crevice corrosion of the neck/head taper (Figure 6).

Our data indicates that the modular ADEPT prosthesis using a Corail Stem has excellent functional results but does cause significantly higher serum concentrations of metal ions. This finding is not unexpected and is attributable to the additional ion generating articulation at the head/neck interface. The clinical significance of the higher metal ion concentration, without toxicity, remains unclear [23]. More research is in progress regarding this.

The study is limited by duration of follow up and small patient numbers. As a retrospective analysis, some

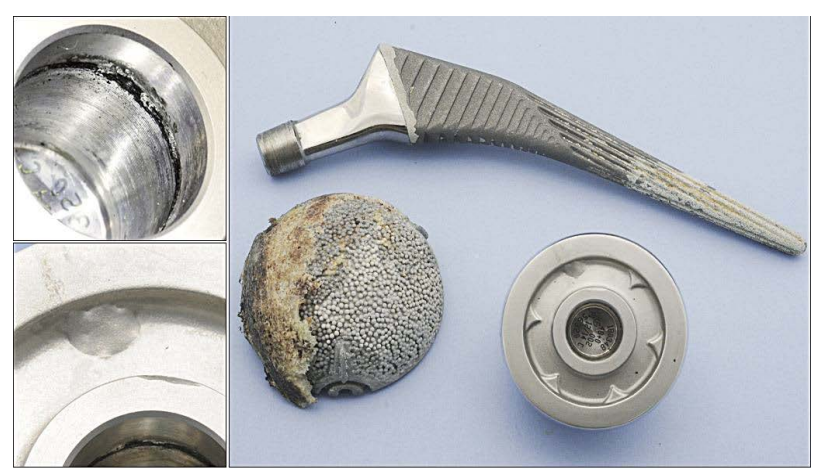

Figure 6. Retrieved implant-56 mm acetabular component, $50 \mathrm{~mm}$ head. patient selection bias is present, with slightly older, heavier patients being selected for the modular implant group. Further recruitment of patients using the modular system is not possible, as the implant has been withdrawn.

Concerns common to metal-on-metal systems include the release of metal (Cobalt and Chromium) ions from the implant, which are systemically detectable [24]. The long term effect of high serum metal ion concentrations is not known, but they may be genotoxic and can cross biological barriers. Short-term effects include neurological and visual disturbances, endocrine dysfunction, cardiac arrhythmias and cardiomyopathy. Iliopsoas and capsular impingement can occur as a size effect of the femoral head component and low head:neck ratio. Pseudotumour formation and acute lymphocytic vascular-associated lesions (ALVAL) are also reported as complications following metal-on-metal arthroplasty.

\section{Conclusion}

There may still be a place for metal-on-metal arthroplasty in carefully selected patients using a correctly inserted ADEPT prosthesis. Functional outcome is excellent, compared with total hip arthroplasty. Ongoing follow up of the patients in this cohort will reveal if trunnion corrosion is a critical problem with the ADEPT modular head on a Corail stem.

\section{REFERENCES}

[1] P. Wiles, “The Surgery of the Osteoarthritic Hip,” British Journal of Surgery, Vol. 45, No. 193, 1938, pp. 488-497. http://dx.doi.org/10.1002/bjs.18004519315

[2] J. M. Cuckler, "The Rationale for Metal-On-Metal Total Hip Arthroplasty,” Clinical Orthopaedics and Related Research, Vol. 441, 2005, pp. 132-136.

[3] M. T. Clarke, P. Lee and R. N. Villar, "Dislocation after Total Hip Replacement in Relation to Metal-On-Metal Bearing Surfaces,” The Journal of Bone \& Joint Surgery. British Volume, Vol. 85, No. 5, 2003, pp. 650-654.

[4] I. C. Clarke and M. T. Manley, "Implant Wear Symposium 2007 Engineering Work Group. How Do Alternative Bearing Surfaces Influence Wear Behavior?” Journal of the American Academy of Orthopaedic Surgeons, Vol. 16, Suppl. 1, 2008, pp. S86-S93.

[5] N. M. Bernthal and P. C. Celestre, "Disappointing ShortTerm Results with the DePuy ASR XL Metal-On-Metal Total Hip Arthroplasty," The Journal of Arthroplasty, Vol. 27, No. 4, 2012, pp. 539-544. http://dx.doi.org/10.1016/j.arth.2011.08.022

[6] W. T. Long and M. Dastane, "Failure of the Durom Metasul Acetabular Component," Clinical Orthopaedics and Related Research, Vol. 468, No. 2, 2010, pp. 400-405. http://dx.doi.org/10.1007/s11999-009-1071-8

[7] K. A. Kindsfater, C. J. Sychterz Terefenko and T. A. 
Gruen, "Minimum 5-Year Results of Modular Metal-OnMetal Total Hip Arthroplasty," The Journal of Arthroplasty, Vol. 27, No. 4, 2012, pp. 545-550. http://dx.doi.org/10.1016/j.arth.2011.07.002

[8] A. J. Smith, P. Dieppe, K. Vernon, M. Porter and A. W. Blom, "On Behalf of the National Joint Registry of England and Wales. Failure Rates of Stemmed Metal-OnMetal Hip Replacements: Analysis of Data from the National Joint Registry of England and Wales,” Lancet, Vol. 380, No. 9855, 2012, pp. 1759-1766. http://dx.doi.org/10.1016/S0140-6736(12)60989-1

[9] The Adept Resurfacing System, 2013. http://www.matortho.com/medical-professionals/adept-re surfacing.aspx

[10] J.-P. Vidalain, "Twenty-Year Results of the Cementless Corail Stem,” International Orthopaedics (SICOT), Vol. 35, No. 2, 2011, pp. 189-194. http://dx.doi.org/10.1007/s00264-010-1117-2

[11] D. W. Murray, R. Fitzpatrick, K. Rogers, H. Pandit, D. J. Beard and A. J. Carr, "The Use of the Oxford Hip and Knee Scores," The Journal of Bone \& Joint Surgery. British Volume, Vol. 89-B, No. 8, 2007, pp. 1010-1014. http://dx.doi.org/10.1302/0301-620X.89B8.19424

[12] N. Bellamy, W. W. Buchanan, C. H. Goldsmith, J. Campbell and L. W. Stitt, "Validation Study of WOMAC: A Health Status Instrument for Measuring Clinically Important Patient Relevant Outcomes to Antirheumatic Drug Therapy in Patients with Osteoarthritis of the Hip or Knee,” The Journal of Rheumatology, Vol. 15, No. 12, 1988, pp. 1833-1840.

[13] H. Amstutz, B. Thomas, R. Jinnah, et al., "Treatment of Primary Osteoarthritis of the Hip. A Comparison of Total Joint and Surface Replacement Arthroplasty,” The Journal of Bone \& Joint Surgery, Vol. 66, 1984, p. 228

[14] A. Nilsdotter and A. Bremander, "Measures of Hip Function and Symptoms: Harris Hip Score (HHS), Hip Disability and Osteoarthritis Outcome Score (HOOS), Oxford Hip Score (OHS), Lequesne Index of Severity for Osteoarthritis of the Hip (LISOH), and American Academy of Orthopedic Surgeons,” Arthritis Care \& Research, Vol. 63, 2011, pp. S200-S207.

[15] T. A. Gruen, G. M. McNeice and H. C. Amstutz, ““Modes of failure," of Cemented Stem-Type Femoral Components: A Radiographic Analysis of Loosening," Clinical
Orthopaedics and Related Research, 1979, pp. 17-27.

[16] R. C. Johnston, R. H. Fitzgerald Jr., W. H. Harris, et al., "Clinical and Radiological Evaluation of total Hip Replacement,” The Journal of Bone \& Joint Surgery. American Volume, Vol. 72-A, 1990, pp. 161-168.

[17] R. T. Steffen, H. P. Pandit, J. Palan, D. J. Beard, R. Gundle and P. McLardy-Smith, "The Five-Year Results of the Birmingham Hip Resurfacing Arthroplasty: An Independent Series,” The Journal of Bone \& Joint Surgery. British Volume, Vol. 90-B, No. 4, 2008, pp. 436-41. http://dx.doi.org/10.1302/0301-620X.90B4.19648

[18] J. G. DeLee and J. Charnley, "Radiological Demarcation of Cemented Sockets in Total Hip Replacement," Clinical Orthopaedics and Related Research, 1976, pp. 20-32.

[19] C. A. Engh, J. D. Bobyn and A. H. Glassman, "PorousCoated Hip Replacement," The Journal of Bone \& Joint Surgery. British Volume, Vol. 69-B, 1987, pp. 45-55.

[20] A. F. Brooker, J. W. Bowerman, R. A. Robinson, L. H. Riley, "Ectopic Ossification following Total Hip Replacement. Incidence and a Method of Classification," The Journal of Bone \& Joint Surgery. American Volume, Vol. 55, 1973, pp. 1629-1632.

[21] Australian Orthopaedic Association National Joint Replacement Registry 2012.

https://aoanjrr.dmac.adelaide.edu.au/documents/10180/60 142/Annual\%20Report\%202012?version=1.3\&t=136122 $\underline{6543157}$

[22] N. M. Desy, S. G. Bergeron, A. Petit, O. L. Huk and J. Antoniou, "Surgical Variables Influence Metal Ion Levels after Hip Resurfacing," Clinical Orthopaedics and Related Research, Vol. 469, No. 6, 2011, pp. 1635-1641. http://dx.doi.org/10.1007/s11999-010-1636-6

[23] K. J. Bozic, J. Browne, C. J. Dangles, P. A. Manner, A. J. Yates and K. L. Weber, "Modern Metal-On-Metal Hip Implants," The Journal of the American Academy of Orthopaedic Surgeons, Vol. 20, No. 6, 2012, pp. 402-406. http://dx.doi.org/10.5435/JAAOS-20-06-402

[24] R. K. Hallows, C. E. Pelt, J. A. Erickson and C. L. Peters, "Serum Metal ion Concentration: Comparison between Small and Large Head Metal-On-Metal Total Hip Arthroplasty," The Journal of Arthroplasty, Vol. 26, No. 8, 2011, 1176-1181.

http://dx.doi.org/10.1016/j.arth.2010.11.004 